\title{
Effect of supplemental UV-A irradiation in solid-state lighting on the growth and phytochemical content of microgreens**
}

\author{
A. Brazaityte $\dot{e}^{1 *}$, A. Viršile ${ }^{1}$, J. Jankauskiene $\dot{e}^{1}$, S. Sakalauskiene $\dot{e}^{1}$, G. Samuoliene $^{1}$, R. Sirtautas ${ }^{1}$, \\ A. Novičkovas ${ }^{2}$, L. Dabašinskas ${ }^{2}, J$. Miliauskienè $\dot{1}^{1}$,V. Vaštakaitè ${ }^{1}$, A. Bagdonavičiené ${ }^{1}$, and P. Duchovskis ${ }^{1}$ \\ ${ }^{1}$ Institute of Horticulture, Lithuanian Research Centre for Agriculture and Forestry, Kaunas str. 30, LT-54333 Babtai, \\ Kaunas distr., Lithuania \\ ${ }^{2}$ Institute of Applied Research, Vilnius University, Sauletekio al. 9-III, LT-10222 Vilnius, Lithuania
}

Received October 9, 2013; accepted November 14, 2014

\begin{abstract}
A b s t r a c t. In this study, we sought to find and employ positive effects of UV-A irradiation on cultivation and quality of microgreens. Therefore, the goal of our study was to investigate the influence of 366, 390, and $402 \mathrm{~nm}$ UV-A LED wavelengths, supplemental for the basal solid-state lighting system at two UV-A irradiation levels on the growth and phytochemical contents of different microgreen plants. Depending on the species, supplemental UV-A irradiation can improve antioxidant properties of microgreens. In many cases, a significant increase in the investigated phytochemicals was found under 366 and $390 \mathrm{~nm}$ UV-A wavelengths at the photon flux density $\left(12.4 \mu \mathrm{mol} \mathrm{m} \mathrm{m}^{-2} \mathrm{~s}^{-1}\right)$. The most pronounced effect of supplemental UV-A irradiation was detected in pak choi microgreens. Almost all supplemental UV-A irradiation treatments resulted in increased leaf area and fresh weight, in higher 2,2-diphenyl-1-picrylhydrazyl free-radical scavenging activity, total phenols, anthocyanins, ascorbic acid, and $\alpha$-tocopherol.

$\mathrm{K}$ e y w o r d s: ultraviolet-A, microgreens, growth, antioxidants
\end{abstract}

\section{INTRODUCTION}

Microgreens are seedlings of vegetables and herbs that are grown to fully opened cotyledons or the first true leaf stage. They are harvested at 7-20 days after germination, depending on the species. Due to a variety of flavours, colours, and textures, microgreens may be used as ingredients in salads, soups, sandwiches and so on (Treadwell et al., 2010; Xiao et al., 2012). They may contain much higher levels of bioactive compounds such as vitamins, mine-

\footnotetext{
*Corresponding author e-mail: a.brazaityte@1sdi.lt

**This work was funded from the Research Council of Lithuania by a grant No. SVE-03/2011, 2011-2014.
}

rals, and antioxidants than mature plants or seeds (Xiao et al., 2012). Nowadays, this type of vegetables is assigned to the group of 'functional foods' that have health promoting or disease preventing properties. About $80-100$ crops and crop varieties may be cultivated as microgreens. It is most popular to grow microgreens from cabbage, beet, kale, kohlrabi, mizuna, mustard, radish, Swiss chard, and amaranth (Treadwell et al., 2010). They can be cultivated in fields or greenhouses and growth chambers under artificial light (Samuoliene et al., 2013; Treadwell et al., 2010; Xiao et al., 2012). High-pressure sodium lamps - an artificial light source - are still popular for supplemental lighting in greenhouses due to their high electrical efficiencies, long operating life, and a wide spectrum of light (Wheeler, 2008). However, recent technologies, such as solid-state lighting, based on light-emitting diodes (LEDs) propose more progressive properties and capabilities. LEDs have a narrow light spectrum, low power consumption, and emit less heat. One of the main advantages of LEDs is the ability to control the spectral output of the lighting system. LEDs are available in the spectral range from near ultraviolet (UV) to near infrared (IR): thus, lighting spectra can be adapted for specific crops and optimized for maximum production without wasting energy on nonproductive wavelengths (Morrow, 2008). The small scale, integrity of LEDs, and attractive design possibilities further expand the growing opportunities of microgreens. They can be grown not only in greenhouses or growth chambers, but also in various 
indoor spaces in restaurants, hospitals, kindergartens, and residential houses. Literature data show that different plants are successfully cultivated under various lighting combinations of blue, red, and far-red LEDs (Stutte et al., 2009; Tarakanov et al., 2012). However, microgreens are generally grown from seeds of open-field vegetables that are physiologically adapted to natural sunlight. It is known that solar UV radiation can cause various responses in higher plants and it is traditionally divided into three wavelength ranges. UV-C (200-280 nm) is very harmful to living organisms, but is absorbed almost completely by the ozone layer of the atmosphere and is not important under natural solar irradiation (Hollósy, 2002). UV-B (280-320 nm) represents only $1.5 \%$ of the total solar spectrum and a greatest portion of it is absorbed by the ozone layer, but can induce a variety of damaging effects in plants. The level of such radiation is affected by changes in stratospheric ozone depletion, so most investigations have focused on UV-B (Hollósy, 2002; Zhou et al., 2007). According to literature data, UV-B reduced plant height, leaf area and length, fresh and dry biomass, and such response depends on the irradiation intensity level, environmental conditions, plant species (Krizek et al., 1998; Tsormpatsidis et al., 2008; Turcsányi and Vass, 2000). Moreover, the change in various internal plant parameters also depends on different levels of UV-B radiation. A high level of UV-B causes serious damage to DNA, membranes, and proteins, decreases the chlorophyll content, and has a negative effect on photosynthesis (Hollósy, 2002; Tsormpatsidis et al., 2008). However, a low level of UV-B stimulates accumulation of UV-absorbing pigments and increases the concentration of flavonoids and anthocyanins (Tsormpatsidis et al., 2008; Zhou et al., 2007). UV-A (320-400 $\mathrm{nm})$ represents about $6.3 \%$ of solar radiation that penetrates the atmosphere to reach the earth surface. It is a less harmful part of UV and is reported to diminish the damaging effect of UV-B (Hollósy, 2002; Zhou et al., 2007). A high level of UV-A sometimes causes similar responses as a low level of UV-B irradiation: necrosis or impairment of the photosynthesis system (Turcsányi and Vaas, 2000; Zhou et al., 2007). A low level of UV-A may increase the content of photosynthetic pigments as well as antioxidant compounds and stimulate plant growth (Brazaitytè et al., 2010; Helsper et al., 2003; Tsormpatsidis et al., 2008). Microgreen cultivation under controlled conditions without UV radiation could impair their nutritional quality. For example, Iwai et al. (2010) stated that it is difficult to harvest perilla with high internal quality in the greenhouse, because it generally is cultivated in the open field and requires full sunlight for efficient growth. The positive effects of UV-A suggest a possibility to use low levels of UV-A to increase the content of various plant phytochemicals that have human health-promoting activity (Helsper et al., 2003). Some studies of the UV-A effect on plants were carried out using various short-wave cutoff films (Tsormpatsidis et al., 2008). Only in recent years,
UV-A LEDs were used for plant growing experiments as a part of different lighting systems (Brazaityte et al., 2009; 2010; Li and Kubota, 2009) or as a sole source of light (Lee et al., 2010; Phyo and Chung, 2013). However, these studies deal with one or another UV-A wavelength effect. In this study, we sought to find and employ positive effects of UV-A irradiation on cultivation and internal quality of microgreens. Therefore, the goal of our study was to investigate the influence of 366, 390, and $402 \mathrm{~nm}$ UV-A LED wavelengths, supplemental for the basal solid-state lighting (LED) system at two UV-A irradiation levels on the growth and phytochemical contents of different microgreen plants.

\section{MATERIALS AND METHODS}

The experiments were carried out at the Institute of Horticulture, Lithuanian Research Centre of Agricultural and Forestry Science. Microgreens of basil (Ocimum basilicum L., Sweet Genovese), beet (Beta vulgaris L., Bulls Blood), and red pak choi (Brassica rapa var. chinensis, Rubi) were grown to harvest time (respectively 10, 14, and 20 days) in a growth chamber on a peat substrate (Profi 1, JSC Durpeta, Lithuania) (pH 6). The average amount of nutrients $\left(\mathrm{mg} \mathrm{l}^{-1}\right)$ in the substrate was as follows: $\mathrm{N}-110, \mathrm{P}_{2} \mathrm{O}_{5}$ $-50, \mathrm{~K}_{2} \mathrm{O}-160$, microelements - Fe, Mn, Cu, B, Mo, Zn. Electrical conductivity was $0.5-0.7 \mathrm{mS} \mathrm{cm} \mathrm{cm}^{-1} .1 \mathrm{~g}$ of basil, $3.5 \mathrm{~g}$ of beet, and $1 \mathrm{~g}$ of red pak choi seeds (CN Seeds Ltd., UK) were seeded into 0.51 vessels $(18 \times 11 \times 6 \mathrm{~cm})$, which represented one replicate. Four vessels were used for each species. The vessels were arranged randomly and were systematically rotated every day for improving the uniformity of the light environment. The plants were watered when needed. The photoperiod was $16 \mathrm{~h}$, day/night temperature $21 / 17^{\circ} \mathrm{C}$, and the average of relative air humidity $-65 \%$.

The microgreens were cultivated under custom-made lighting equipment containing separate modules for parallel growth runs under individually controlled illumination conditions. The light-emitting diodes were mounted on a flat aluminium heat sink with reflectors and were arranged to ensure optimal homogeneity of the flux. Each module contained four basal groups of high-power LEDs with different peak wavelengths. The main photosynthetically active photon flux was provided by deep red, red, and blue LEDs with the peak wavelength of 665,638 , and $447 \mathrm{~nm}$, respectively (Luxeon Rebel LXM3-PD01-0300, Luxeon LXHL-LD3C, Luxeon LXHL-LR3C, respectively; all by Philips Lumileds Lighting Co., USA). The far-red component of the spectrum was provided by LEDs with the peak wavelength of $731 \mathrm{~nm}$ (L735-05-AU, Epitex Inc., Japan). Three modules were equipped with the fifth group of supplemental high-power UV LEDs emitting at $366 \mathrm{~nm}$ (NCSU033B, Nichia Corp., Japan), 390 nm (NCSU034B, Nichia Corp., Japan), and $402 \mathrm{~nm}$ (ACULED VHL ACL01-SC-UUUU-E05-C01-L-U000, PerkinElmer, Inc., USA). The emission spectra of the LEDs were measured 
using a photonic multichannel analyser (Hamamatsu PMA12, Japan) and are presented in Fig. 1. All LED groups were driven independently by custom-made high-power current regulators with digital control. Lighting regime was preprogrammed by a controller unit using a remote computer. Each module has an illuminated area of $0.28 \mathrm{~m}^{2}$ sufficient for simultaneous growth of vegetable plants in amounts large enough for acquisition of statistically reliable data.

Two experiments were carried out to determine the UV-A effects on the microgreens. Table 1 presents the lighting regimes of both growth runs. The overall photon flux density of blue, red, deep red, and far red LEDs in each lighting module was $300 \mu \mathrm{mol} \mathrm{m}^{-2} \mathrm{~s}^{-1}$ at the crop level. The regimes differed in the UV LEDs photon flux density. The first treatment (EXP1) was provided with the supplemental UV-A photon flux density of $6.2 \mu \mathrm{mol} \mathrm{m}{ }^{-2} \mathrm{~s}^{-1}$ (lower UV-A irradiance level) and in the second treatment (EXP2) the supplemental UV-A photon flux density was increased by a factor of 2 (higher UV-A irradiance). A module without UV LEDs was used for reference growth runs.

After the lighting experiment, microgreen cotyledons with stems were harvested just above the ground. Samples were taken from the central vessel part, leaving plants $1.5 \mathrm{~cm}$ from vessel edges as guard. Plant height, hypocotyl length, leaf area, and fresh weight were measured for determining the UV-A effect on microgreen growth. Leaf area was measured using a 'WinDias' leaf area meter (Delta-T Devices Ltd, UK).

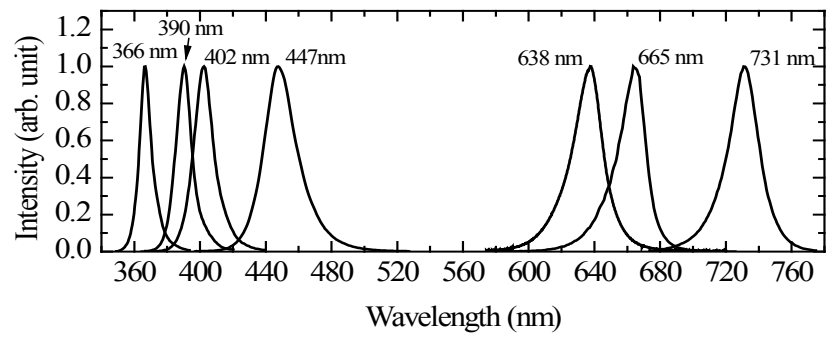

Fig. 1. Normalized emission spectra of the LEDs used in the lighting equipment.
Conjugated biological samples of the fresh matter of randomly selected plants were used for phytochemical analysis. Antioxidant activity of microgreen fresh matter $\left(\mu \mathrm{mol} \mathrm{g}{ }^{-1}\right)$ was evaluated spectrophotometrically as the 2,2-diphenyl-1-picrylhydrazyl (DPPH) free-radical scavenging capacity (Ragaee et al., 2006) of methanolic extracts (fresh tissue ground with liquid nitrogen and diluted with $80 \%$ methanol at the ratio $1: 10(\mathrm{~m} / \mathrm{v}))$. The absorbance was scanned for $16 \mathrm{~min}$ at $515 \mathrm{~nm}$ (Thermospectronic, USA).

The total content of phenolic compounds $\left(\mathrm{mg} \mathrm{g}^{-1}\right)$ in microgreen fresh matter was determined by preparing methanolic extracts (fresh tissue ground with liquid nitrogen and diluted in $80 \%$ methanol at the ratio $1: 10(\mathrm{~m} / \mathrm{v})$ ) and using a colorimetric Folin-Ciocalteau method (Ragaee et al., 2006). Absorbance was measured at $765 \mathrm{~nm}$ using a Genesys 6 spectrophotometer (Thermospectronic, USA) against water as a blank. Total phenolics were determined by a calibration method using gallic acid as a standard.

The total amount of anthocyanins $\left(\mathrm{mg} \mathrm{g}^{-1}\right)$ was determined using the spectrophotometric $\mathrm{pH}$-differential method proposed by Stanciu et al. (2009). Fresh tissue was ground with liquid nitrogen and diluted with $2 \% \mathrm{HCl}$ in methanol. The absorption values of the extract in $0.025 \mathrm{M}$ potassium chloride ( $\mathrm{pH} 1.0)$ or $0.4 \mathrm{M}$ sodium acetate buffer $(\mathrm{pH} 4.5)$ were measured at 420,520, and $700 \mathrm{~nm}$ wavelengths. Anthocyanins were expressed as a cyanidin 3-glucoside equivalent, $\mathrm{mg} \mathrm{g}^{-1}$ in fresh microgreen weight, using a molar extinction coefficient of $25740 \mathrm{M}^{-1} \mathrm{~cm}^{-1}$ and molecular weight of $485 \mathrm{mg} \mathrm{mol}^{-1}$.

Ascorbic acid ( $\mathrm{mg} \mathrm{g}^{-1}$ in fresh weight) was assessed by a spectrophotometric method (Janghel et al., 2007), based on methyl viologen reduction to a stable blue free radical ion. Samples were prepared by homogenising fresh plant material with an oxalic acid solution. The coloured radical ion was measured at $600 \mathrm{~nm}$ and ascorbic acid contents were evaluated using the calibration method.

The $\alpha$-tocopherol content ( $\mathrm{mg} \mathrm{g}^{-1}$ in fresh weight) was evaluated according to Fernandez-Orozco et al. (2003) using the high performance liquid chromatography (HPLC)

T a b l e 1. Photon flux densities at the crop level in $\mu \mathrm{mol} \cdot \mathrm{m}^{-2} \mathrm{~s}^{-1}$ produced by LEDs with the indicated peak emission wavelengths in two plant growth experiments denoted as EXP1 and EXP2

\begin{tabular}{|c|c|c|c|c|c|c|c|}
\hline \multirow{5}{*}{ Experiments } & \multicolumn{7}{|c|}{ Illumination } \\
\hline & \multicolumn{3}{|c|}{ Supplemental } & \multicolumn{4}{|c|}{ Basal } \\
\hline & \multicolumn{3}{|c|}{ UV } & \multirow{2}{*}{$\begin{array}{l}\text { blue } \\
447\end{array}$} & \multirow{2}{*}{$\begin{array}{l}\text { red } \\
638\end{array}$} & \multirow{2}{*}{$\begin{array}{c}\text { deep red } \\
665\end{array}$} & \multirow{2}{*}{$\begin{array}{c}\text { far red } \\
731 \\
\end{array}$} \\
\hline & 366 & 390 & 402 & & & & \\
\hline & \multicolumn{7}{|c|}{$(\mathrm{nm})$} \\
\hline \multicolumn{8}{|c|}{ Photon flux density $\left(\mu \mathrm{mol} \mathrm{m} \mathrm{m}^{-2} \mathrm{~s}^{-1}\right)$} \\
\hline EXP1 & 6.2 & 6.2 & 6.2 & 21 & 122 & 155 & 2.2 \\
\hline EXP2 & 12.4 & 12.4 & 12.4 & 21 & 122 & 155 & 2.2 \\
\hline
\end{tabular}


method. Fresh microgreen tissue was ground with liquid nitrogen and hexane extracts $(1: 10 \mathrm{~m} / \mathrm{v})$ were prepared. An HPLC 10A system equipped with RF-10A fluorescence detector (Shimadzu, Japan) and Pinacle II silica column, 5 - $\mu \mathrm{m}$ particle size, $150 \times 4.6 \mathrm{~mm}$ (Restek, USA) was used for the analysis. The peak was detected using an excitation wavelength of $295 \mathrm{~nm}$ and emission wavelength of $330 \mathrm{~nm}$. The mobile phase was $0.5 \%$ isopropanol in hexane, flow rate $1 \mathrm{ml} \mathrm{min}^{-1}$.

The nitrate concentration was measured by a potentiometric method (Geniatakis et al., 2003) using an ion meter (Oakton, USA) with a nitrate-selective electrode (ColeParmer, USA). Samples were prepared from $\sim 40 \mathrm{~g}$ fresh microgreen tissue per sample that was dried at $105^{\circ} \mathrm{C}$ for $24 \mathrm{~h}$ and ground. The ionic strength adjustor (ISA) contained $0.1 \mathrm{M} \mathrm{Al}_{2}\left(\mathrm{SO}_{4}\right)_{3}$. The weighed dry sample $(0.2 \mathrm{~g})$ was diluted with $20 \mathrm{ml}$ water-ISA solution $(50 / 50 \% \mathrm{v} / \mathrm{v})$. All measurements were performed after the sensor signal had been stabilized for $3 \mathrm{~min}$.

The flavonol and chlorophyll content was determined by a non-destructive method using a flavonol and chlorophyll meter Dualex4 (Dynamax Inc., USA).

Three analytical replications of DPPH, phenols, anthocyanins, ascorbic acid, a-tocopherol, nitrate, and ten biological replications of chlorophylls, flavonols, and growth parameters were performed for each treatment. Statistical analysis was performed using STATISTICA 7.0 for Windows, and differences from the reference were compared using Student t-test. Mean differences were considered significant when $\mathrm{p} \leq 0.05$.

\section{RESULTS}

The microgreens showed distinct growth responses to different treatments of supplemental UV-A in basal illumination (Table 2). A trend was noticed that, with increasing supplemental UV-A wavelength (from 366 to $402 \mathrm{~nm}$ ) in the basal lighting, the microgreen height and hypocotyl length increased at both UV-A LEDs intensity levels. However, at the higher (EXP2 $-12.4 \mu \mathrm{mol} \mathrm{m}^{-2} \mathrm{~s}^{-1}$ ) UV-A irradiance intensity level, basil grew significantly higher under supplemental $402 \mathrm{~nm}$ wavelength light and pak choi - under supplemental $390 \mathrm{~nm}$ wavelength light. Meanwhile, at this irradiance level, supplemental UV-A LEDs had no significant effect on the length of the microgreen hypocotyls. At lower (EXP1 $6.2 \mu \mathrm{mol} \mathrm{m}^{-2} \mathrm{~s}^{-1}$ ) UV-A LEDs irradiance, only supplemental $402 \mathrm{~nm}$ wavelength light caused a significant increase in the microgreen height and hypocotyl length.

Leaf area of basil and pak choi significantly increased under all supplemental UV-A LEDs lighting at the higher intensity level, although basil under supplemental $390 \mathrm{~nm}$ light (Table 2). Meanwhile, at a lower intensity level (EXP1), the leaf area of basil and beet significantly increased under supplemental $366 \mathrm{~nm}$ wavelength light and that of pak choi under supplemental $402 \mathrm{~nm}$ light. Similar trends were found for fresh weight of these microgreens, although there were no significant differences between the treatments at the higher UV-A intensity level (EXP2). However, at the lower intensity level, supplemental UV-A LEDs light caused a significant or slight increase in fresh weight of basil, a decrease in this index in beet, and no effect in pak choi. The same trends were found for the dry weight of the microgreens (data not shown).

Neither the different UV-A wavelengths nor the UV-A LEDs intensity level had a significant effect on basil and beet chlorophyll index (Table 2). Meanwhile, supplemental UV-A increased this index in pak choi. Supplemental $390 \mathrm{~nm}$ irradiation at both illumination levels had the most significant effect on the increase in the chlorophyll index.

Phytochemical concentrations and antioxidant activity in the microgreens were also significantly affected by the different supplemental UV-A treatment. Our data revealed that almost all supplemental UV-A resulted in increased DPPH free-radical scavenging activity of the microgreens (Table 3). Depending on the microgreen species and level of exposure, most notable effects were induced by supplemental $366 \mathrm{~nm}$ irradiance. Total phenolic compounds were found to be species depended. All supplemental UV-A significantly increased their content in basil at the higher intensity level, but had no effect at lower irradiance. The lower UV-A LEDs irradiance level (EXP1) had no effect on the phenol content in beet, but at higher intensity (EXP2) their content significantly increased with the supplemental $402 \mathrm{~nm}$ treatment. Supplemental $366 \mathrm{~nm}$ irradiance significantly increased total phenolic compounds in pak choi at both applied UV-A irradiance levels (Table 3). The flavonol index determined by a non-destructive method showed a similar trend to that in phenols, although a significant increase in beet and pak choi flavonol index was found under supplemental $366 \mathrm{~nm}$ irradiance at the higher intensity level (Fig. 1). The total anthocyanin concentration at the higher UV-A intensity (EXP2) was the greatest under supplemental $366 \mathrm{~nm}$ and $390 \mathrm{~nm}$ in beet and pak choi. Meanwhile, their content decreased in basil (Table 3). At the lower irradiance level (EXP1), such supplementation had no effect on the total anthocyanin concentration in all microgreens. Supplemental $366 \mathrm{~nm}$ irradiance caused a significant decrease in ascorbic acid in basil at both illumination levels. Its concentration in beet significantly decreased with supplemental $366 \mathrm{~nm}$ at the higher intensity, but significantly increased at the lower. All supplemental UV-A wavelengths increased the ascorbic acid concentration in pak choi at the higher intensity level. Meanwhile, at the lower one, their concentration significantly increased with supplemental $366 \mathrm{~nm}$ and significantly decreased with supplemental $390 \mathrm{~nm}$ and $402 \mathrm{~nm}$. At the higher irradiance level (EXP2), all supplemental UV-A had a positive effect on the $\alpha$-tocopherol content in the microgreens, except basil, where supplemental 390 or $402 \mathrm{~nm}$ irradiance resulted in a significantly decreased content thereof. Supplemental $366 \mathrm{~nm}$ irradiance had the greatest effect on the $\alpha$-tocopherol content in all microgreens. Meanwhile, the lower intensity 
T a b l e 2. The effect of UV-A on growth parameters and the chlorophyll index of the microgreens

\begin{tabular}{|c|c|c|c|c|c|c|}
\hline \multicolumn{2}{|c|}{ Effect } & $\begin{array}{l}\text { Height } \\
(\mathrm{cm})\end{array}$ & $\begin{array}{l}\text { Hypocotyls } \\
\text { length }(\mathrm{cm})\end{array}$ & Leaf area $\left(\mathrm{cm}^{2}\right)$ & $\begin{array}{c}\text { Fresh } \\
\text { weight }(\mathrm{mg})\end{array}$ & $\begin{array}{l}\text { Chlorophyll } \\
\text { index }\end{array}$ \\
\hline \multicolumn{7}{|c|}{ Basil } \\
\hline \multirow{4}{*}{ EXP1 } & Basal & $2.48 \pm 0.11$ & $1.36 \pm 0.13$ & $1.00 \pm 0.06$ & $27.3 \pm 1.6$ & $25.8 \pm 1.1$ \\
\hline & +366 & $2.63 \pm 0.08$ & $1.51 \pm 0.09$ & $1.05 \pm 0.04 \mathrm{~A}$ & $39.0 \pm 2.3 \mathrm{~A}$ & $26.8 \pm 0.9$ \\
\hline & +390 & $2.70 \pm 0.07$ & $1.71 \pm 0.09 \mathrm{~A}$ & $0.80 \pm 0.05$ & $27.9 \pm 0.6$ & $24.6 \pm 1.4$ \\
\hline & +402 & $2.93 \pm 0.08 \mathrm{~A}$ & $1.87 \pm 0.08 \mathrm{~A}$ & $0.89 \pm 0.03$ & $35.4 \pm 1.9 \mathrm{~A}$ & $28.7 \pm 0.9$ \\
\hline \multirow{4}{*}{ EXP2 } & Basal & $3.25 \pm 0.06$ & $2.01 \pm 0.11$ & $1.60 \pm 0.13$ & $48.8 \pm 2.9$ & $30.4 \pm 1.1$ \\
\hline & +366 & $3.12 \pm 0.12$ & $1.81 \pm 0.07$ & $2.18 \pm 0.14 \mathrm{~A}$ & $55.8 \pm 4.6$ & $29.2 \pm 0.8$ \\
\hline & +390 & $3.27 \pm 0.10$ & $1.98 \pm 0.12$ & $1.43 \pm 0.07$ & $52.3 \pm 1.5$ & $30.5 \pm 1.7$ \\
\hline & +402 & $3.73 \pm 0.10 \mathrm{~A}$ & $2.32 \pm 0.10$ & $2.35 \pm 0.08 \mathrm{~A}$ & $55.5 \pm 4.1$ & $29.3 \pm 1.2$ \\
\hline \multicolumn{7}{|c|}{ Beet } \\
\hline \multirow{4}{*}{ EXP1 } & Basal & $4.70 \pm 0.13$ & $1.94 \pm 0.16$ & $2.46 \pm 0.15$ & $94.1 \pm 5.3$ & $19.5 \pm 1.1$ \\
\hline & +366 & $5.38 \pm 0.19 \mathrm{~A}$ & $2.04 \pm 0.18$ & $3.72 \pm 0.23 \mathrm{~A}$ & $89.9 \pm 9.6$ & $16.8 \pm 1.3$ \\
\hline & +390 & $4.94 \pm 0.13$ & $1.95 \pm 0.14$ & $2.73 \pm 0.08$ & $75.7 \pm 5.0 \mathrm{~B}$ & $17.7 \pm 0.8$ \\
\hline & +402 & $5.49 \pm 0.16 \mathrm{~A}$ & $2.56 \pm 0.16 \mathrm{~A}$ & $2.75 \pm 0.14$ & $80.3 \pm 1.3 \mathrm{~B}$ & $18.4 \pm 0.8$ \\
\hline \multirow{4}{*}{ EXP2 } & Basal & $6.92 \pm 0.20$ & $3.47 \pm 0.12$ & $3.45 \pm 0.22$ & $152.0 \pm 7.4$ & $25.2 \pm 0.8$ \\
\hline & +366 & $6.74 \pm 0.30$ & $3.54 \pm 0.16$ & $3.14 \pm 0.23$ & $131.1 \pm 7.3$ & $25.0 \pm 0.8$ \\
\hline & +390 & $7.16 \pm 0.22$ & $3.85 \pm 0.16$ & $3.95 \pm 0.28$ & $174.9 \pm 12.2$ & $25.1 \pm 1.0$ \\
\hline & +402 & $6.77 \pm 0.16$ & $3.76 \pm 0.12$ & $3.59 \pm 0.21$ & $155.7 \pm 13.7$ & $22.9 \pm 0.8$ \\
\hline \multicolumn{7}{|c|}{ Pak choi } \\
\hline \multirow{4}{*}{ EXP1 } & Basal & $5.95 \pm 0.09$ & $3.79 \pm 0.07$ & $3.02 \pm 0.13$ & $95.6 \pm 3.8$ & $23.9 \pm 0.84$ \\
\hline & +366 & $5.92 \pm 0.14$ & $3.73 \pm 0.12$ & $2.98 \pm 0.08$ & $93.2 \pm 5.9$ & $28.8 \pm 0.97 \mathrm{~A}$ \\
\hline & +390 & $5.96 \pm 0.12$ & $3.91 \pm 0.13$ & $2.71 \pm 0.12$ & $88.6 \pm 3.0$ & $30.5 \pm 1.28 \mathrm{~A}$ \\
\hline & +402 & $6.29 \pm 0.06 \mathrm{~A}$ & $4.03 \pm 0.06 \mathrm{~A}$ & $3.77 \pm 0.15 \mathrm{~A}$ & $98.9 \pm 6.0$ & $29.4 \pm 1.26 \mathrm{~A}$ \\
\hline \multirow{4}{*}{ EXP2 } & Basal & $6.00 \pm 0.13$ & $3.99 \pm 0.08$ & $2.67 \pm 0.07$ & $98.6 \pm 2.7$ & $29.1 \pm 1.7$ \\
\hline & +366 & $6.34 \pm 0.14$ & $4.10 \pm 0.12$ & $4.25 \pm 0.18 \mathrm{~A}$ & $109.0 \pm 9.5$ & $29.2 \pm 0.9$ \\
\hline & +390 & $6.57 \pm 0.11 \mathrm{~A}$ & $4.37 \pm 0.18$ & $4.21 \pm 0.15 \mathrm{~A}$ & $106.5 \pm 6.7$ & $34.4 \pm 1.5 \mathrm{~A}$ \\
\hline & +402 & $6.28 \pm 0.09$ & $4.10 \pm 0.09$ & $3.93 \pm 0.13 \mathrm{~A}$ & $98.7 \pm 3.6$ & $29.6 \pm 1.5$ \\
\hline
\end{tabular}

A - significantly higher than the control (basal illumination), B - significantly lower than the control. Significance level: $\mathrm{p}<0.05$ (t-test). 
T a b l e 3. Effect of UV-A on antioxidant contents of microgreens

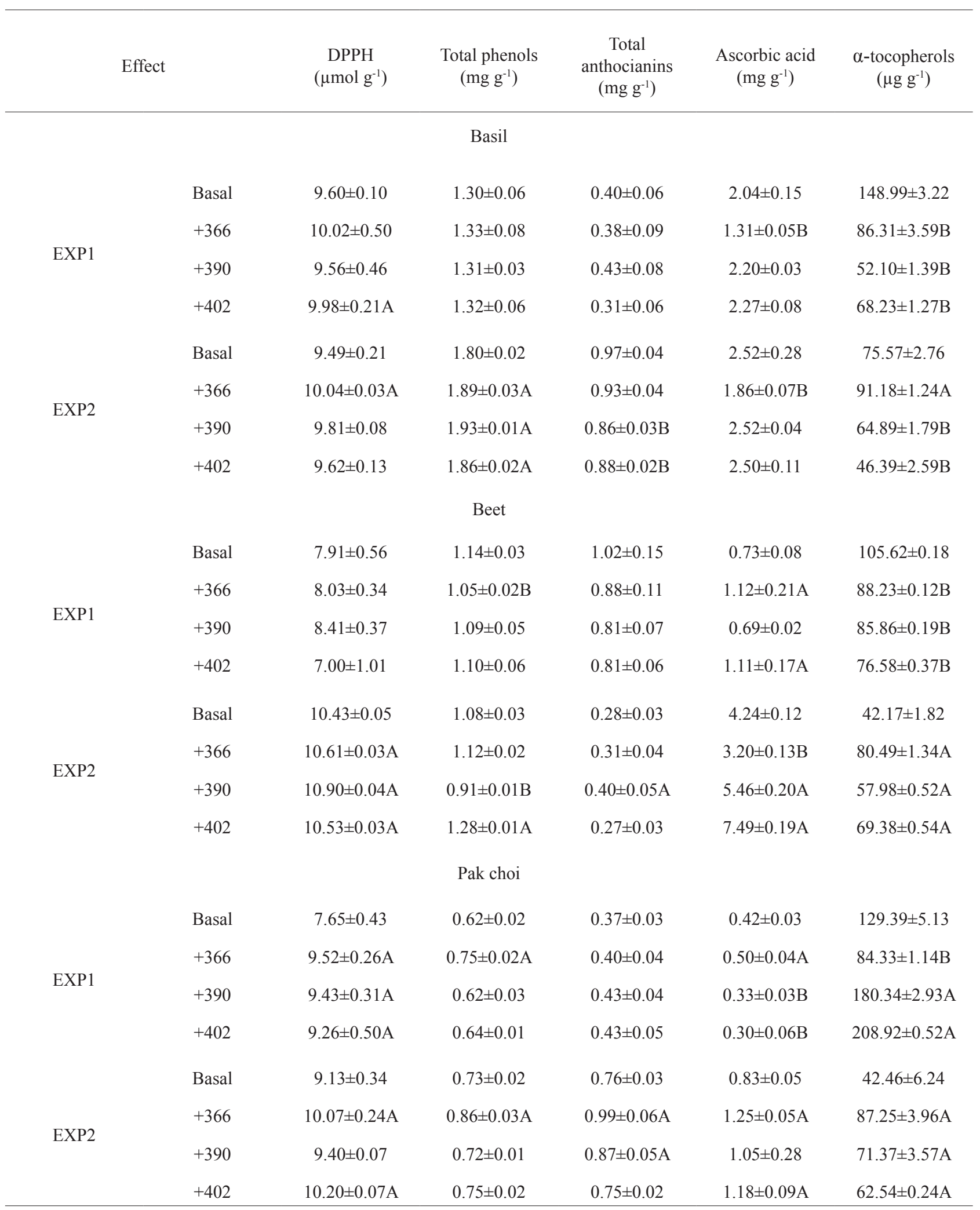

Explanations as in Table 2. 
supplemental UV-A irradiation (EXP1) resulted in a significantly decreased $\alpha$-tocopherol content in the microgreens, except supplemental 390 or $402 \mathrm{~nm}$ irradiance, which caused its increase in pak choi (Table 3).

Supplemental UV-A irradiance increased the nitrate content in the microgreens at both UV-A LEDs intensities used (Fig. 3). The only exception was pak choi, where supplemental UV-A irradiance at the higher intensity level (EXP2) decreased the nitrate content. At lower intensity (EXP2), only supplemental $366 \mathrm{~nm}$ UV-A decreased nitrate content in basil.

\section{DISCUSSION}

Our study revealed that the UV-A irradiation effect on the microgreens was species and intensity dependent. It was determined overall trend that the supplemental UV-A irradiance increased plant height and hypocotyl length, or had no effect on it, but no decrease in elongation of the microgreens was detected in any lighting treatment. Generally, UV-A related plant responses depend on the blue-UVA light photoreceptor, ie the cryptochrome (Lin, 2000), and activation thereof by UV-A generally determines stem growth inhibition (Silva et al., 2005). However, no inhibitory effects of UV-A on the height and hypocotyls have been found in our study. Generally, supplemental UV-A had no damaging influence on leaf area and biomass parameters of the microgreens. According to literature data, supplemental UV-A did not significantly affect biomass of pea seedlings in greenhouse conditions (Wenke and Qichang, 2012) and biomass of baby lettuce cultivated in growth chambers under white fluorescence lamps (Li and Cubota, 2009). Tsormpatsidis et al. (2008) reported that total aboveground dry weight was positively correlated with the degree of UV radiation cutoff transmitted by films. Our investigations revealed a different effect of UV-A irradiation on the different microgreen species. A most remarkable effect of the supplemental UV-A was found on pak choi growth at the higher intensity level. Irradiation with all supplemental UV-A wavelengths increased leaf area and plant biomass, but a greater positive effect was observed under 366 and $390 \mathrm{~nm}$. Meanwhile, the effect of supplemental UV-A irradiation on leaf area and biomass of basil and beet depended on the wavelengths and intensity level. The reaction of different species to supplemental UV-A was also determined in our earlier investigations with cucumber and tomato. Supplementation of the basal high-power solid-state lighting with the UV-A LEDs also resulted in increased leaf area and fresh and dry mass of tomato, but it decreased the growth and development of cucumber transplants (Brazaityte et al., 2009, 2010). Various studies showed a UV-A inhibition effect on plant growth in different plant species and suggested that the decrease under UV irradiation was induced by damage to the photosynthetic apparatus by damaging photosystem II (Krizek et al., 1998; Turcsányi and Vass, 2000). Our investigations revealed that supplemental UV-A irradiation had no negative effect on the chlorophyll content. Meanwhile, all supplemental UV-A even increased the chlorophyll index of pak choi at the lower intensity level. Supplemental $390 \mathrm{~nm}$ irradiation at both intensity levels had the most significant effect on the increase in this index. Our earlier investigations revealed no UV-A effects on photosynthesis pigments of cucumber and tomato, but decreased the chlorophyll $\mathrm{a}$ and $\mathrm{b}$ ratio in cucumber (Brazaityte et al., 2009, 2010).

Plants may produce secondary products to protect them against UV light damage. Such metabolites as phenolics, flavonoids, and anthocyanins also play an important role in promoting human health and preventing diseases (Iwai et al., 2010; Tsormpatsidis et al., 2008). Literature data show different plant responses to UV-A to accumulation of these phytochemicals. Li and Cubota (2009) reported an increase in the anthocyanin concentration in baby lettuces under

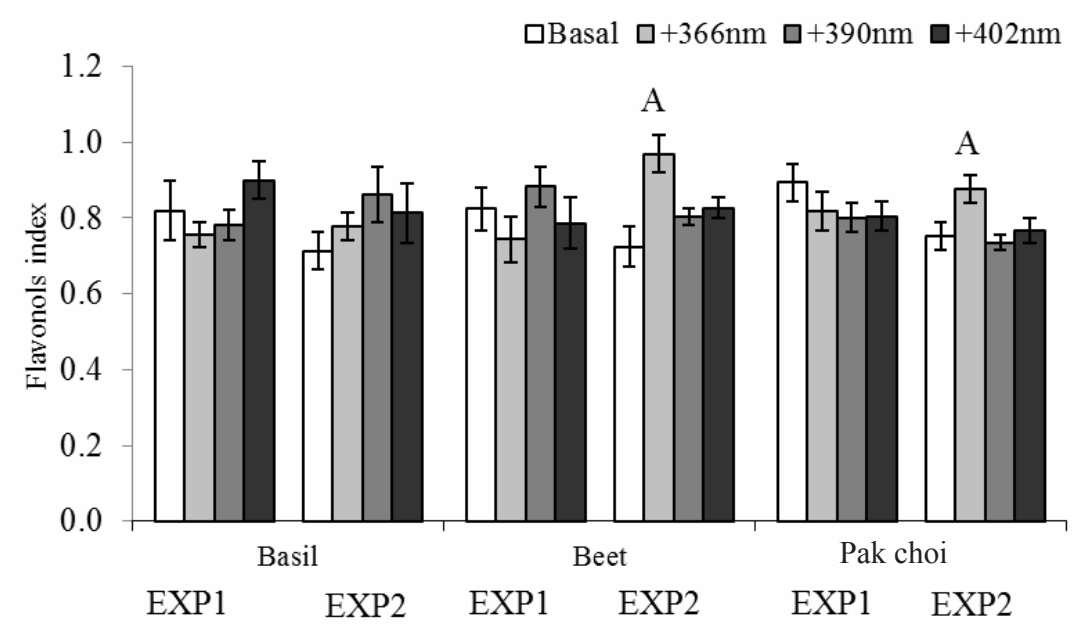

Fig. 2. The effect of UV-A on the flavonol index of the microgreens: A - significantly higher than the control (basal illumination), Significance level: $\mathrm{p}<0.05$ (t-test). 
UV-A LEDs at a 373-nm peak, but no effect on phenolic compounds. Tsormpatsidis et al. (2008) investigated UV transparent and blocking films and determined that radiation at $370-400 \mathrm{~nm}$ had no significant effects on the content of anthocyanin, flavonoid, and phenolic compounds in lettuce, and suggested that shorter wavelength UV might be more effective in increasing the concentration of these phytochemicals. Meanwhile, shorter wavelength UV caused a decrease in lettuce biomass. Supplemental UV-A with the main wavelength of $365 \mathrm{~nm}$ did not significantly affect the contents of phenolic compounds and flavonoids of pea seedlings, but decreased the shoot anthocyanin content (Wenke and Qichang, 2012). According to the data of Iwai et al. (2010), artificial illumination with UV-A enhanced the content of polyphenols in perilla, compared to greenhouse-grown plants. Total phenolic compounds and DPPH radical-scavenging activity of barley leaves cultivated under UV-A only slightly increased than of those grown under fluorescent lamps (Lee et al., 2010). Our data revealed that almost all investigated supplemental UV-A, especially $366 \mathrm{~nm}$, increased the DPPH free-radical scavenging activity of the microgreens. Meanwhile, total phenolic compounds were found to be species dependent and the most notable effect was observed at the higher UV-A irradiance intensity level. The flavonol content measured by the non-destructive method as an index showed a similar trend as the total content of phenols. Therefore, this method could be used as quick assessment of phenolic compounds in microgreen leaves under various lighting conditions. Supplemental 366 and $390 \mathrm{~nm}$ at the higher intensity level showed an upward trend in the total anthocyanin concentration in beet and pak choi, but a decrease in basil. Supplemental UV-A irradiance at the lower intensity level had no effect on the total anthocyanin concentration in the microgreens. Our results agree with Kataoka et al. (2003), who showed that the anthocyanin content in berry skins was increased with increasing intensity of UV-A irradiation. Zhou et al. (2007) reported that only UV-A alone induced anthocyanin biosynthesis and application of red or far-red with UV-A did not affect the rate of UV-A induced anthocyanin accumulation in turnip.

Ascorbic acid in association with other components of the antioxidant system protects plants against oxidative damage, resulting from various stress factors, including UV-A (Wenke and Qichang, 2012). Our results showed that supplemental $366 \mathrm{~nm}$ at the higher irradiance level had a harmful effect on the ascorbic acid content in basil and beet, but induced an opposite effect in pak choi. Meanwhile, the longer wavelength of UV-A in many cases had a positive effect on the ascorbic acid content. Other authors reported that UV-A irradiation had no effect on its content (Li and Kubota, 2009; Wenke and Qichang, 2012).

$\alpha$-Tocopherol is the major vitamin E compound found in leaf chloroplasts and its level depends on the level of stress and species sensitivity to stress. Under high intensity light stress, tocopherol levels increase dramatically (MunneBosh, 2005). Our studies revealed that at the higher intensity level practically all supplemental UV-A wavelengths increased the $\alpha$-tocopherol content in the microgreens. Supplemental $366 \mathrm{~nm}$ irradiance had the greatest effect on the $\alpha$-tocopherol content. Meanwhile, at lower intensity, supplemental UV-A irradiation mainly decreased the $\alpha$-tocopherol content in the microgreens. It can be stated that shorter supplemental UV-A wavelengths at the higher intensity level were stressful for the microgreens, and the $\alpha$-tocopherol content increased as protection against stress.

The nitrate content is one of the quality characteristics of vegetables. Light quantity and quality have been known as one the major factors affecting nitrate contents in vegetables due to regulation of nitrate reductase activity (Lin et al., 2013; Santamaria, 2006). In our experiments, it was found that supplemental UV-A irradiance increased the nitrate content in the microgreens, except for pak choi under the higher UV-A irradiance level. UV-A and blue lightrelated plant responses depend on the same light photoreceptor. Literature data show that blue light increased the nitrogen content and was less efficient in stimulation of nitrate reduction in plants than red light (Lin et al., 2013). On the other hand, UV-A exposure increased the nitrate content in the microgreens, but generally their maximum level was about $400 \mathrm{mg} \mathrm{kg}^{-1}$ and such an increase should not have a negative effect on human health. According to various accepted nitrate limits in different countries, their content in fresh leafy vegetables varies from 2000 to $4500 \mathrm{mg} \mathrm{kg}^{-1}$ depending on species (Santamaria, 2006).

Summarizing, our findings and literature data indicate that it is worth to use supplemental UV-A LEDs in developing LED lighting systems for microgreen cultivation. Although the effect was species dependent, the data showed that it is better to choose a shorter wavelength and higher intensity of UV-A. Such illumination had no damaging effect on the growth parameters of the microgreens, but showed a trend to increase DPPH free-radical scavenging activity, total phenols, anthocyanins, and $\alpha$-tocopherol.

\section{CONCLUSIONS}

1. Depending on species, UV-A irradiation supplemental for basal LED illumination can improve the antioxidant properties of microgreens. In many cases, a significant increase was found under the 366 and $390 \mathrm{~nm}$ UV-A wavelengths and the higher intensity photon flux density 12.4 $\mu \mathrm{mol} \mathrm{m} \mathrm{m}^{-2} \mathrm{~s}^{-1}$.

2. The most positive effect of supplemental UV-A irradiation in basal illumination was observed on the pak choi microgreens. Almost all supplemental UV-A wavelengths, especially at the photon flux density $12.4 \mu \mathrm{mol} \mathrm{m} \mathrm{m}^{-2} \mathrm{~s}^{-1}$ increased leaf area and fresh weight, DPPH free-radical scavenging activity, total phenols, anthocyanins, ascorbic acid, and $\alpha$-tocopherol. 


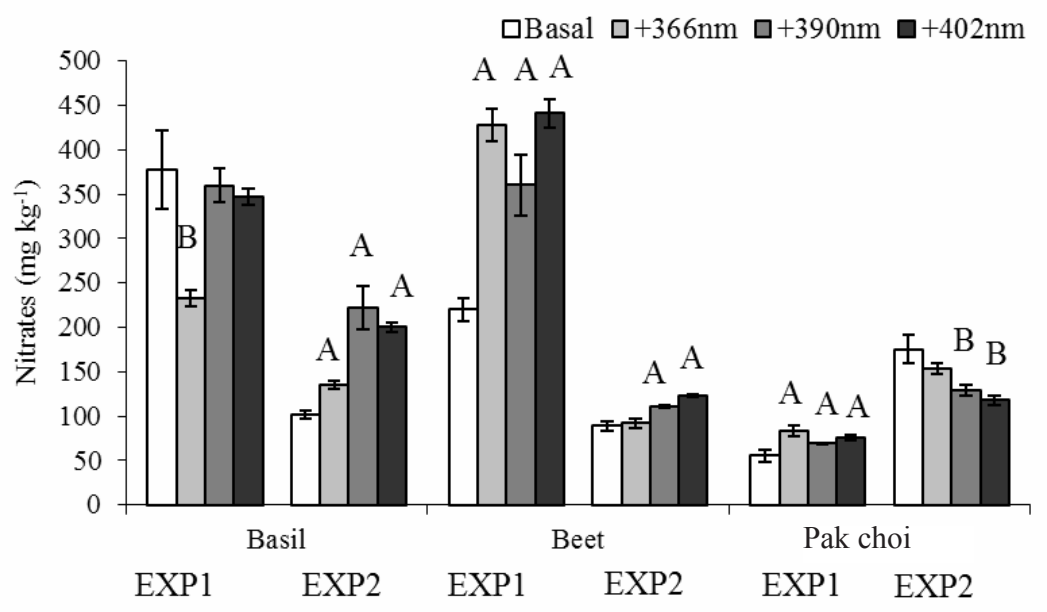

Fig. 3. Effect of UV-A on the nitrate content in the microgreens: A - significantly higher than the control (basal illumination), B - significantly lower than the control. Significance level: $\mathrm{p}<0.05$ (t-test).

\section{REFERENCES}

Brazaitytė A., Duchovskis P., Urbonavičiūtė A., Samuolienė G., Jankauskienė J., Kasiulevičiūtė-Bonakėrè A., Bliznikas Z., Novičkovas A., Breivė K., and Žukauskas A., 2009. The effect of light-emitting diodes lighting on cucumber transplant and after-effect on yield. Zemdirbyste-Agriculture, 96(3), 102-118.

Brazaitytė A., Duchovskis P., Urbonavičiūtė A., Samuolienė G., Jankauskienė J., Sakalauskaitė J., Šabajevienė G., Sirtautas R., and Novičkovas A., 2010. The effect of light-emitting diodes lighting on growth of tomato transplants. Zemdirbyste-Agriculture, 97(2), 89-98.

Fernandez-Orozco R., Zieliński H., and Piskuła M.K., 2003. Contribution of low-molecular-weight antioxidants to the antioxidant capacity of raw and processed lentil seeds. Nahrung/Food, 47(5), 291-299.

Geniatakis E., Fousaki M., and Chaniotakis N.A., 2003. Direct potentiometric measurement of nitrate in seeds and produce. Communications in Soil Science and Plant Analysis, 34, 571-579.

Helsper J.P.F.G., Ric de Vos C.H., Maas F.M., Jonker H.H., van den Broeck H.C., Jordi W., Pot C.S., Keizer L. C.P. and Schapendonk A.H.C.M., 2003. Response of selected antioxidants and pigments in tissues of Rosa hybrida and Fuchsia hybrida to supplemental UV-A exposure. Physiologia Plantarum, 117, 171-178.

Hollósy F., 2002. Effects of ultraviolet radiation on plant cells. Micron, 33, 179-197.

Iwai M., Mari Ohta M., Tsuchiya H., and Suzuki T., 2010. Enhanced accumulation of caffeic acid, rosmarinic acid and luteolin-glucoside in red perilla cultivated under red diode laser and blue LED illumination followed by UV-A irradiation. J. Functional Foods, 2, 66-70.

Janghel E.K., Gupta V.K., Rai M.K., and Rai J.K., 2007. Micro determination of ascorbic acid using methyl viologen. Talanta, 72, 1013-1016.

Kataoka I., Sugiyama A., and Beppu K., 2003. Role of ultraviolet radiation in accumulation of anthocyanin in berries of 'Gros Colman' grapes (Vitis vinifera L.). J. Japanese Society Horticultural Sci., 72, 1-6.
Krizek D.T., Britz S.J., and Mirecki R.M., 1998. Inhibitory effects of ambient levels of solar UV-A and UV-B radiation on growth of cv. New Red Fire lettuce. Physiologia Plantarum, 103, 1-7.

Lee N.Y., Lee M.J. , Kim Y.K., Park J.C , Park H.K., Choi J.S., Hyun J.-N., Kim K.-J., Park K.-H., Jae-Kwon Ko, and Jung-Gon Kim, 2010. Effect of light emitting diode radiation on antioxidant activity of barley leaf. J. Korean Society Applied Biological Chem., 53, 658-690.

Li Q. and Kubota C., 2009. Effects of supplemental light quality on growth and phytochemicals of baby leaf lettuce. Environ. Exp. Botany, 67, 59-64.

Lin C.T., 2000. Blue light plant receptors. Trends in Plant Sci., 5(8), 337-342.

Lin K.-H., Huang M.-Y., Huang W.-D., Hsu M.-H., Yang Z.-W., and Yang C.-M., 2013. The effects of red, blue, and white light-emitting diodes on the growth, development, and edible quality of hydroponically grown lettuce (Lactuca sativa L. var. capitata). Scientia Hort., 150, 86-91.

Morrow R.C., 2008. LED lighting in horticulture. Hort Sci., 43, 1947-1950.

Munne'-Bosch S., 2005. The role of $\alpha$-tocopherol in plant stress tolerance. J. Plant Physiol., 162, 743-748.

Phyo A.K. and Chung N-J., 2013. Response of single leaf photosynthesis and transpiration to red light and UV-A radiation in two different plant-type rice cultivars (Oryza sativa L.), Australian J. Crop Sci., 7(1), 119-129.

Ragaee S., Abdel-Aal E.M., and Maher N., 2006. Antioxidant activity and nutrient composition of selected cereals for food use. Food Chem., 95, 32-38.

Samuolienė G., Brazaitytė A., Jankauskienė J., Viršilè A., Sirtautas R., Novičkovas A., Sakalauskienė S., Sakalauskaitè J., and Duchovskis P., 2013. LED irradiance level affects growth and nutritional quality of Brassica microgreens. Central Eur. J. Biol., 8(12), 1241-1249.

Santamaria P., 2006. Nitrate in vegetables: toxicity, content, intake and EC regulation. J. Sci. Food Agric., 86, 10-17.

Silva N.C.B., Macedo A.F., Lage C.L.S., Esquibel M.A., and Sato A., 2005. Developmental effects of additional ultraviolet a radiation, growth regulators and tyrosine in Alternanthera brasiliana (L.) Kuntze cultured in vitro. Brazilian Archives Biol. Technol., 48(5), 779-786. 
Stanciu G., Lupşor S., and Sava C., 2009. Spectrophotometric characterizations of anthocyans extracted from black grapes skin. Ovidijus University Annals Chemistry, 20(2), 205-208.

Stutte G.W., Edney S., and Skerritt T., 2009. Photoregulation of bioprotectant content of red leaf lettuce with light-emitting diodes. Hort Sci., 44, 79-82.

Tarakanov I., Yakovleva O., Konovalova I., Paliutina G., and Anisimov A., 2012. Light emitting diodes: on the way to combinatorial lighting technologies for basic research and crop production. Acta Hort., 956, 171-178.

Treadwell D.D., Hochmuth R., Landrum L., and Laughlin W., 2010. Microgreens: A new specialty crop. HS1164. Institute of Food and Agricultural Sciences, University of Florida.

Tsormpatsidis E., Henbest R.G.C., Davis F.J., Battey N.H., Hadley P., and Wagstaffe A., 2008. UV irradiance as a major influence on growth, development and secondary products of commercial importance in Lollo Rosso lettuce 'Revolution' grown under polyethylene films. Environ. Exp. Botany, 63, 232-239.
Turcsáinyi E. and Vass I., 2000. Inhibition of photosynthetic electron transport by UV-A radiation targets the photosystem II complex. Phochemistry Photobiol., 72(4), 513-520.

Wenke L. and Qichang Y., 2012. Effects of day-night supplemental UV-A on growth, photosynthetic pigments and antioxidant system of pea seedlings in glasshouse. African J. Biotechn., 11(82), 14786-14791.

Wheeler R.M., 2008. A historical background of plant lighting: an introduction to the workshop. Hort Sci., 43(7), 1942-1743.

Xiao Z., Lester G.E., Luo Y. and Wang Q., 2012. Assessment of vitamin and carotenoid concentrations of emerging food products: edible microgreens. J. Agric. Food Chem., 60, 7644-7651.

Zhou B., Li Y., Xu Z., Yan H., Homma S., and Kawabata S., 2007. Ultraviolet A-specific induction of anthocyanin biosynthesis in the swollen hypocotyls of turnip (Brassica rapa). J. Exp. Botany, 58(7), 1771-1781. 